\title{
The Role of Formal and Informal Forces in Shaping Consumption and Implications for a Sustainable Society. Part I
}

\author{
Oksana Mont ${ }^{1, *}$ and Kate Power ${ }^{2}$
}

1 The International Institute for Industrial Environmental Economics, Lund University, P.O. Box 196, Tegnersplatsen 4, SE-221 00 Lund, Sweden

2 Copenhagen Resource Institute, Højbro Plads 4, DK-1200 Copenhagen, Denmark; E-Mail: kapow@etc.mim.dk

* Author to whom correspondence should be addressed; E-Mail: oksana.mont@iiiee.lu.se; Tel.: +46-46-222-0250; Fax: +46-46-222-0230.

Received: 27 May 2010; in revised form: 17 June 2010 / Accepted: 7 July 2010 /

Published: 16 July 2010

\begin{abstract}
Addressing climate change and the collapse of ecosystems without threatening the economy, while simultaneously improving the well-being of all people and ensuring social justice and equality, seems to be the largest challenge in the history of mankind. So far, all the efforts to address growing environmental and human problems through technological solutions and policy measures have been largely outpaced by growing population and increasing consumption levels. Therefore, an understanding of the essential driving forces and complexities of consumption, and of how environmental impacts from rising consumption can be reduced, is becoming increasingly important. This understanding can be achieved by analyzing not only economic frameworks, political settings, business models, and technological innovations, but also social norms, psychological factors, and collective and individual decision-making processes. This article, Part I, provides a meta-analysis of the main political, economic, technological, and business drivers of contemporary consumption and offers a systematic discussion of the relevance of these factors for the instigation of change towards sustainable patterns and levels of consumption. The main conclusion from Part I and II is that a systems-thinking approach is required in order to understand how various political, technical, social, economic, and psychological drivers overlap and influence each other in creating our consumer society.
\end{abstract}


Keywords: formal institutions; consumption; sustainable consumption

\section{Introduction}

It is becoming increasingly clear that consumption patterns and levels are as responsible for the deteriorating state of the environment as production patterns. Until recently, environmental debates have mainly focused on improving the efficiency of production processes and products. However, many studies now demonstrate the significant contribution of consumption to the overall environmental impact of our society [1,2]. Therefore, addressing the environmental consequences of our daily purchasing choices and of macro-level consumption patterns is becoming an important focal point of research and societal efforts. However, before engaging in the discourse on possible strategies for reducing environmental impacts, it is important to understand the reasons behind the current consumption patterns and levels, the main drivers for consumption, and the main barriers for people and various actors in society to shift towards more sustainable consumption patterns and levels.

The main goal of this paper is to map out, from a multi-disciplinary perspective, the most critical factors that have influenced and shaped contemporary consumption patterns and levels. The secondary goal is to understand how the knowledge of factors shaping consumption can be useful for discussing strategies for achieving sustainable consumption.

Part I of the paper analyzes formal institutional factors, which are seen as influencing consumption from economic, political, technological innovation, and business perspectives, and their implications for the discourse on sustainable consumption. Part II of the paper analyzes the social and psychological factors that shape the consumption patterns of individuals and groups.

\section{Economic Framework}

The economic framework within which our society operates influences the way we consume and produce. But who defines the principles on which the economic framework is based? For the last couple of centuries, classical and neoclassical economics provided such principles. One of these is the consumer sovereignty principle [3]. According to this principle, the tastes and preferences of consumers are given and cannot be influenced from outside; they can only be efficiently satisfied by the market. According to the neoclassical perspective, policy makers should be reluctant to instigate measures that intervene in consumers' sovereignty and should treat the consumption domain as being beyond the reach of legal influence. Consumer sovereignty is often used to justify the deficit of consumption-oriented policies, even though the notion per se is disputed. First of all, according to other schools of thought, tastes and preferences do change in the long term under the influence of education, advertising and cultural assumptions [4], as well as social norms and infrastructure. Secondly, there are examples of governmental intervention in consumer choice when it comes to consumption of, for example, tobacco, pornography, drugs, and firearms: government regulation of such markets is justified on the grounds of these products' impacts on health and safety. Similarly, governments can interfere in markets of product groups that have significant environmental impacts; this is already done in some cases, e.g., PCB or asbestos use. They can become even more involved in 
issues of choice editing, assisting or prompting businesses to remove the most environmentally damaging products from the market [5]. However, such interference into the sphere of products that have adverse environmental effects is often criticized by industry representatives.

According to neoclassical economics, one of the main drivers of consumption is the insatiable need of individuals to maximize their utility, which is achieved through a process of choosing among alternatives available on the market [6-8]. Consumer choice is in turn influenced by income, price, and the time available for shopping [9]. Thus, policy makers and businesses have a possibility of influencing consumers' demands, and thereby shape consumption patterns and levels, by influencing prices and income levels. This understanding leads to the proliferation of financial mechanisms in the economic sphere, e.g., taxes, subsidies, etc.

Level of income greatly influences consumption levels; ability to earn depends on personal skills, the amount of time for work, and how well the skills are applied (i.e., labor productivity). Of course, income level also depends on the type of work chosen or available. For example, an advertising executive may earn ten-times as much as a teacher with the same level of skills, qualifications and hours of work. Generally, higher incomes are possible as workers' qualifications increase, and as technological improvements provide higher labor and resource productivity. Higher labor and resource productivity reduce manufacturing costs and the final prices of products and services. Since levels of consumption are linked to the available budget, consumers are assumed to be interested in increasing personal incomes as a means of increasing their happiness. However, Easterlin [10] suggested that happiness did not depend on absolute, but on relative income-one's income level compared to the level of income of one's reference group. If there is a surplus between one's income and expenditure, then increasing income may also have another contribution to consumption in the form of savings. In this case, the excess income is turned into savings, which eventually end up as investments, further contributing to economic growth. Shifting income to leisure time (working fewer hours for a reduced income and having more leisure time) has been named as one of the potential areas for governments to address unsustainable consumption [11-13].

Consumption is also stimulated by competitive financial institutions offering attractive credits to consumers. Research demonstrates the direct correlation between residential prices and consumption growth, since people tend to borrow money using the value of their homes as collateral $[14,15]$. In many countries, this situation leads to the accumulation of consumer debt [16]. The misuse of credit can lead to personal and national budget overshoot and result in personal bankruptcies or (inter)national financial crises. There is thus a need to rethink the social costs of using personal credit to stimulate consumption [5].

Another important factor that influences consumption is working hours. Along with increasing personal incomes, productivity growth could (in theory) reduce work time and provide more opportunities for leisure. The reduction of working hours does take place (e.g., in most of the countries in Western Europe), but at a rate that is far below productivity growth, and in some countries, e.g., Japan and USA, working hours tend to increase, sometimes followed by increasing incomes. Higher incomes and less free time may lead to increasing consumption, e.g., buying different time-saving energy-using devices, restaurant meals, or toys for children to compensate for lack of time spent with them [17]. On the other hand, the question of whether time gained from shorter working hours is spent on non-commoditized activities or on more consumption is still debatable, e.g., [18] vs. [19]. Shop 
opening hours are another time-related factor that directly influence consumption patterns and levels, by increasing the flexibility of the shopping experience. Studies show that despite the advent of convenience shops and online shopping, an average American consumer spends about 38 minutes shopping for consumer goods per day [20]. Having suitable shopping hours is therefore an important factor that affects when, what, where, and at what price products are consumed. For example, the changing lifestyles of modern consumers, toward becoming more flexible and harried, mean that nighttime supermarkets are highly appreciated by parts of the population [21].

Although seeing consumption as a proxy for well-being is one of the main drivers of consumption, a growing number of scholars suggest that material wealth fails to provide happiness. In fact, the opposite seems to be true. Social life and leisure suffer as one's time and energy are directed toward obtaining more money and material goods [22-25]. Indeed, many consumers in modern industrialized countries feel trapped in a work-and-spend cycle where they are trying to compensate excessive stress and a widening social and cultural vacuum through increasing consumerism [26].

To summarize, it seems that "economics in its mainstream neoclassical form is failing to provide an intellectually coherent explanation of economic reality, especially with regard to such issues as the nature of markets, environmental degradation, persistent poverty, and household production, and is therefore responsible for much flawed policy advice" [27]. It is also clear that neoclassical economics has failed to provide an understanding of people in their role as consumers and citizens that is useful for policy development in the field of sustainability. Other schools of economics, such as ecological economics or behavioral economics, might provide useful insights for developing policies addressing sustainable consumption.

\section{Policies and Policy Instruments}

One important factor in modern consumption patterns is the regulatory setting. Public policy, as one of the important institutions, shapes nearly all consumer decisions through its influence on different aspects of everyday life - from a simple permit to sell a product, to regulating prices of products and services. Policies and policy instruments may have direct or indirect influence on consumption patterns and levels. For example, consumer policy directly influences consumption by aiming to protect consumer sovereignty and consumer rights for access to products and services of decent quality that do not aversely affect human health [28]. These goals are specifically defined in the European Consumer Policy strategy for 2007-2013 as to "equip ... the consumer with the skills and tools to fulfil their role in the modern economy; [to make] markets deliver for them and [to ensure] effective protection from the risks and threats they cannot tackle as individuals" [29]. Although Consumer policy plays an extremely important role for securing fair and equitable access to goods and services across the EU, it has been criticized for lacking ambition with regard to addressing total levels of consumption, although the recent communication acknowledged that the European Consumer Policy "can provide the market tools to empower citizens, as consumers, to make sustainable environmental choices" [29].

Innovation policy is an example of policy that indirectly influences consumption by promoting technical innovations at national and regional levels [30]. It supports and stimulates the emergence of new products, thereby indirectly contributing to increased consumption. On the other hand, innovation 
leads to the emergence of more environmentally sound products, which reduces the impacts of products. However, it has been shown that efficiency improvements are often compensated for by increased levels of consumption - the so-called rebound effect [31-33]. Another important feature of the innovation process is its speed, which seems to be increasing in the last decades, urging consumers to buy new products even if old versions are still functional [34]. Innovation as a process is also sometimes responsible for creating "artificial" human needs by inventing products that are not "originally" demanded by the market: "technological advances are creating needs that people learn to feel when being faced with new products" ([35]: p. 41). However, once a technical solution has been developed, marketing and advertising are used to create needs and wants for it among consumers. Innovation policy supports and protects supply-side driven innovation and often lacks a comprehensive understanding of consumption processes within environmental limits, primarily because these issues are simply outside its main focus area. Innovation policy has, therefore, received significant criticism in recent years from environmental and sustainability scientists [36].

Trade policies accelerate resource extraction and consumption by connecting countries and regions rich in natural resources (typically economically developing countries with low consumption levels) to countries of high demand for these resources (typically economically developed countries with high consumption levels). The current trade system thus reinforces the unequal distribution and consumption of resources in the world. In addition to inequality issues, the current trade heavily relies on transport of these resources and goods as the distances between the resources and consumers have drastically increased in the past several decades [37].

When looking at these policies from a perspective of sustainable consumption, it becomes clear that both trade policy and innovation policy are often based on the growth mentality, without consideration for the limits of non-renewable resources and the assimilating capacity of the Earth.

In addition to policies, there are a number of policy instruments that directly or indirectly affect consumption. Their design also mainly relies on the consumer behavior model of neoclassical economics: that inappropriate price signals and a lack of trustworthy and authoritative information are the main barriers to a more sustainable behavior in consumers, who would otherwise be committed to the goals of sustainable development. Therefore, a range of consumption-oriented policy instruments have been developed based on these assumptions. The majority of them focus on adjusting for market failures by providing more accurate information to consumers (e.g., ecolabeling and awareness raising campaigns) and in a few cases, by correcting prices through taxes and charges.

The level of taxes on various products and services clearly influences the final price, and thereby directly affects consumption patterns and levels. One example is the difference in mobility patterns between Europe and the USA, which can be partially explained by the tax system on fuels. According to many studies, European taxes on gasoline resulted in a more energy-efficient vehicle fleet, less driving, and more extended use of public transport systems [38]. Taxes and charges are quite effective instruments for changing consumer behavior, compared to, for example, information-based instruments [39]. They can contribute to sustainable consumption by incorporating the environmental and social costs of products and processes into final prices [40] and by taxing environmentally damaging products and activities [41-43]. This would have an effect on both industries and consumers, and would make environmentally and socially responsible choices economically beneficial and normalized in society. On the other hand, taxes as an economic instrument often face the problem of 
public acceptance, e.g., [44] and heavy business lobbying. This explains why the internalization of environmental and social costs, or Ecological Tax Reform [45], although being discussed for more than a decade now, is still in its early stage of implementation. Studies demonstrate that "environmental policy packages" tend to have a more significant effect on individual behavior when implemented in combination with investments in related environmental services" [46]. For example, in the area of transport, fuel tax and congestion charges tend to have a greater influence on people's behavior when complemented by investments in public transport services, such as bicycle paths and buses.

Ecolabeling and similar information tools face a difficulty in that consumers have been shown to become easily confused by the amount and the diversity of the information $[47,48]$. In addition, sociological and environmental studies demonstrate that provision of information does not necessarily lead to changes in attitudes, and even when it does, the change in attitudes does not always translate into behavior change [49,50]. Campaigns, especially the so-called "simple and painless" campaigns, can also give the false impression that by taking small steps, big changes can be realized. This is however not supported by scientific evidence, which demonstrates that if “everyone does a little, we'll achieve only a little" [51]. Finally, a major weakness of information instruments, and specifically of awareness-raising campaigns, stems from the complexity of individuals' interactions with society and with institutions and infrastructures that are largely not conducive to living sustainable lifestyles [52]. More details on the effectiveness of information instruments can be found in Part II of this study.

More comprehensive policy studies demonstrate that there is a lack of policy instruments which directly shape consumption into a more sustainable direction [39]. At best, these instruments shape consumption patterns by propagating markets of green products. The first decades of environmental policy have largely failed to acknowledge the pivotal role of changing consumers' lifestyles and consumption levels. Instead, policy focused solely on consumers' patterns of purchasing goods and services, i.e., policy only promoted green products rather than sustainable ways of life with significantly lower environmental impacts from consumption. Seeing people only as consumers, means that consumer decisions to delay or avoid purchase - to stay away from shopping and the market economy - are not taken into consideration [53]. This also robs people of another alternative- to satisfy their needs in less materialistic ways and to aspire to personal development rather than to "keeping up with the Jones". The current policy instruments for sustainable consumption are limited to the choices consumers can make within the formal market. This means that people who are unable, cannot afford to, or are simply not willing to participate in the market have little opportunity to be heard [52].

\section{Technological Innovation}

The Industrial Revolution was one of the most important drivers for reaching current standards of living and levels of consumption, and technological innovation undoubtedly played a key role in it. The increase in work productivity achieved through the specialization of labor and technological modernization led to a giant leap in production output of both industry and agriculture, which in turn enabled increased consumption levels. Since 1750 the global industrial output has increased by a factor of 100, and in the last hundred years, output has grown 40-fold [54]. Since the population increased at 
a much slower pace, this meant a steep increase in per capita consumption levels. Scientific and technological innovation contributed to this process in three ways [55] by:

- Replacing labor with capital, resources, and energy, leading to increased labor productivity and rising levels of per capita production and consumption;

- Developing a large number of new products and services that did not exist before, and the need for which was not apparent until they had been designed;

- Increasing the efficiency of production processes, leading to decreasing costs of goods and services, thereby stimulating their consumption.

Specifically, the development of general-purpose technologies, such as electricity, the internal combustion engine, and communication technology, triggered consumption [56]. Developments in medical science and technology have also indirectly increased consumption levels by decreasing infant mortality, lengthening life expectancy, and by introducing new drugs and increasing possibilities for medical intervention [57]. Technological development led to increases in population in industrialized countries during the 19th-20th centuries, but recently, technology transfer to developing countries has been named as the main cause of the global population explosion [58]. Specifically, energy technologies are responsible for population increase [59].

To keep the economic wheel turning and to satisfy the growing number of consumers with the growing number of products per capita, production systems were and are being made increasingly efficient in terms of labor productivity, but have experienced a much slower increase in resource productivity, with consequent adverse impacts in the form of increased resource extraction and escalating pollution to the environment. The current system of mass production develops and manufactures relatively short-life products [60], with planned obsolescence becoming a science in its own right. For example, cars can potentially be designed and built to last 30 years [61], but the average life time of a modern car is about 10-15 years - they have become fashion items, as have many other products. The positive effect of shortening life cycles is that replacement products might be more efficient. However, looking at the car market, fuel efficiency only started to improve in the last few years and thus upgrading of cars before this time can hardly be justified from the resource use perspective. Designing products for durability, repair, and reuse is not economical, as labor costs in developed countries are prohibitively high, while costs of resources are relatively low. A study demonstrated that during 1981-1994 the price of new TVs increased by 20\%, while the cost of repair work rose by over $150 \%$ ([62]: p. 20). The result of this is that people generally find it cheaper, easier, and more attractive to replace a faulty item by buying a new product, rather than researching how to repair it.

The market mechanism usually helps to move a good from the realm of expensive novelty to the realm of affordable mass products, which enables consumption levels to increase. Practice shows that wealthy individuals are more likely to consume luxury items and are typically early adopters of a new technology, absorbing the initially high costs of innovation. As soon as the market for the early adopters (usually wealthier consumers) saturates, the manufacturers may choose to lower their profit margins or produce similar, but simpler and cheaper products in order to reach the mass consumer [63]. For example, a car was a luxury item in early 1920s, but became affordable to larger groups of American and European consumers as incomes grew in the 1950-1960s. 
As technological improvements are made, the price of new technologies drops and demand increases, allowing the suppliers to benefit from economies of scale. As production volumes increase, so does competition, which further presses down prices, making products more affordable and available to the masses. This leads to an increasing number of products per households. For example, "electronic devices are a growing part of our lives and many of us can count between 20 and 30 separate items in our homes, from major items like televisions to a host of small gadgets" [64]. In addition, households may now own several identical items: more than one phone and computer, TV, and DVD-player, gaming machine, etc.

Technologies generated as stand-alone products at first, may later give rise to a number of support products or to new product systems, infrastructures, social practices, institutions, and even entire cultures. For example, "the purchase of a new iPod may lead to the recognition of a need for accessories, such as a dock, attachment for the car, or a carrying case" ([65]: p. 108).

Both scientific and technological innovation can greatly contribute to creating a more sustainable society. However, we should remember that technology is a double-edged sword: it can serve both constructive and destructive purposes. As demonstrated above, technological innovation is a cause of increasing standards of living across the globe, but is also a reason for increased population and increased levels of consumption. However, technology has an important role to play in reducing both population growth and the negative impacts of consumption. For example, science and technology can play a crucial role in developing and providing effective birth control methods that can prevent population increases. This suggests that technological innovations need to be governed with awareness of moral codes and by prioritizing the common societal good.

New R\&D and innovative technologies are emerging on a daily basis; nanotechnology, medical science, new chemicals, and new composite materials; new products and production processes. So far, however, technological innovation and the policies for promoting it have been largely focused on R\&D spending and on subsidizing specific technologies without much consideration for their impacts on sustainability. National systems of innovation tend to be guided by goals of maximizing competitiveness, rather than by sustainability goals [66]. Thus, a more coherent approach to innovation for a low-carbon sustainable society is needed, including a greater focus on improving the resource efficiency of products and product systems. Together with acknowledging the power of technology, its limitations should not be forgotten, and measures to tackle unsustainable patterns and levels of consumption involving people's aspirations, values, and behaviors need to be devised.

\section{Infrastructure}

Urban planning and construction policies steer public investment in infrastructure and thereby have a significant influence on consumption patterns. Infrastructure is an essential enabling factor for growth of consumption. Its development is partially linked to the cycles of innovation and partially to the changes in demographic trends within society. The latest innovation cycle seems to have emerged in the 1990s and is associated with the innovation of information and communication technologies, and consequently, with the rapid development of related infrastructure [5].

Infrastructure has been seen as both a constraint [67] and a driver of consumption [68-70]. The very nature of infrastructural networks can explain this duality: stability and access on the one hand and rigidity 
and lock-in on the other. Infrastructure is comprised of collective socio-technical systems that are accessible for many users and supported or run by many actors. These systems include mechanisms for the provision of water and sewerage, electricity, and mechanisms for waste management, telephone lines, etc. [71]. The systems usually require consumption in their own right, according to Warde [69], whilst encouraging further consumption of associated products. They create mutual "pathways of dependency" [72] between social and technical parts, between users and providers, between investments and long pay-back periods, between the present and the future. Large investments into these systems stimulate the natural desire of the investors to increase their use or their consumption in order to accelerate return on their investments. In addition to these features, infrastructure has a relatively long life. Therefore, systems of provision may, at a certain point of time, become a barrier to change. This relates to road and bridge networks, as much as to communication lines and electricity grids. One example that can illustrate how infrastructure becomes a burden to society is the telephone landlines network in industrialized countries. With market saturation of mobile phones, the traditional landlines are becoming outdated. It is therefore a strategy for developing countries to leapfrog the stage of infrastructure development for telephone lines and directly invest in mobile network systems.

The idea of pathways of dependency shares certain similarities with the idea proposed by Sanne on "lock-ins" [73]. The lock-in notion highlights how daily practices, technologies, and systems of provision are locked into each other and shape consumption patterns and levels. The most exemplary and interlinked areas are housing and mobility. The existing settlement structure and associated planning procedures for the construction of new cities shape people's behaviour for many years to come. In turn, people's wants and needs also affect the settlement structures. For example, many people prefer living in low-density one-family housing, and this is one of the main contributors to urban sprawl. This facilitates the development of highly dispersed communities, and consequently affects the distances travelled by people between home, work, shopping centres, and other facilities. Covering these distances largely relies on using private cars, and sometimes several cars per family.

A widespread car culture enables retailers to move premises to city outskirts reachable mainly by car, thereby creating social inequality by restricting access to shops for car-less people. This move also deteriorates city centres and shifts shopping, as well as cultural life, to shopping malls, since nowadays they also incorporate cinemas, ice ranges, and bowling halls.

People do not usually have much choice but to use the available infrastructure [74]. Even when people want to live more sustainably, they sometimes find themselves "locked-in" to existing patterns of behaviour by the infrastructure around them, as well as by economic regulations, such as taxation, subsidies etc. that promote certain patterns of behaviour over others [68,71]. For example, various subsidies to the aviation industry ensure that flying is a cheaper alternative to rail or bus travel in many situations, thereby encouraging more unsustainable transport and tourism. One of the important barriers to changing existing infrastructures is, of course, the actors behind these infrastructures, who aim to maximize the return on their investments into the infrastructures. Another consideration is the image created and associated with some infrastructures. Some consumer studies show that people perceive being at the airport as exciting, while the same is not often mentioned about other means of transport [75]. Train stations are seldom perceived as exciting; they are often associated with dirt, noise, and homeless people. Thus, if travelling by buses or trains is to become a viable alternative, investments need to be made not only into hardware - the infrastructure itself, but also into the 
marketing of these means of transportation as cool and modern, emphasizing benefits for people and the environment.

On the other hand, recent ideas of distributed, localized economies are built on totally different principles than those that underpin current infrastructures. In these new systems, people are viewed as active participants in both production and consumption - as the so-called co-providers of utility. The current large-scale, centralized, or highly hierarchical systems of provisions (electricity, water, waste management, etc.) are transformed into small-scale distributed systems of production and consumption that might be interconnected and sell utility to the central network [76]. Examples of these new distributed systems can be found within the energy sector, where communities or individual households install photovoltaic cells or wind power units, or use geothermal energy to produce electricity that covers household needs, with excess sold to the central electricity grid, often at a fixed price that guarantees the individual producer the price, and allows concrete planning of pay-back time for the investment [77].

An important role of sustainable infrastructure is to enable, support, and normalize more sustainable lifestyles. Sustainable infrastructure, with the support of proper policies, should ensure that consumers have the possibility of spending their money on more energy-efficient, low-carbon and socially-responsible infrastructure systems. However, as long as decisions regarding infrastructure are made to satisfy the private interests of a few stakeholders, rather than the long-term societal goals of sustainability and prosperity for all, change towards more sustainable infrastructure is unlikely. Some recent studies depict scenarios of how life in a decarbonised world might look and what kind of infrastructural changes might be needed [78].

\section{Business Factors}

In the classical market economy, the main goal of business is to make money by continuously increasing sales of products and services, linking the volume of profit to the number of products sold. The traditional business model is being perfected all the time to reduce all the expensive inputs and to find various ways of stimulating consumption. As a result, several characteristic features of the current market economy can be identified:

- linear economy supported by the throwaway mentality of producers and consumers that is based on economies of scale of both production and consumption,

- planned obsolescence: manufacturing of short lived average or low quality products, and

- stimulation of ever-growing consumer demand for new products and services.

The emphasis of the market economy on efficient process technologies has led to an enormous increase in labor productivity — on average, a factor of 20 in 150 years [79] — but on the other hand, this emphasis on market economy has not resulted in anywhere near the same level of increase in resource productivity, leading to the current global environmental problems. Planned obsolescence, which is "the production of goods with uneconomically short useful lives so that customers will have to make repeat purchases" [80] is the main building block of the throwaway mentality that turns the wheel of the modern economies. Proponents of planned obsolescence argue that short lived products, which could ultimately serve as a driver for economic growth, may be a necessary condition for technological 
progress and that a pattern of rapidly deteriorating products and fast innovation may be preferred to long-lasting products and slow innovation [81]. "Any method that can motivate the flow of merchandise to new buyers will create jobs and work for industry and hence national prosperity. Our custom of trading in our automobiles every year, of having a new refrigerator, vacuum cleaner, or electric iron every three or four years is economically sound" [82].

Some experts [83,84], supported by a handful of businesses, e.g., Xerox, DuPont, and Interface, propagate a closed-loop economy, designing for long life, as well as design strategies for durability and recycling. Others propagate the so-called service economy as an alternative to the throwaway society [85], in which negative economic impacts from slower throughput of products are offset by repair services, reuse of products, and remanufacturing activities. In practice, however, there is little happening that could indicate that the shift to the service economy or widespread remanufacturing activities is taking place.

On the contrary, we are witnessing the emergence of ever-shortening fashion cycles with companies and retailers advertising new clothing collections every week. New business models have also been developed to stimulate increasing consumption by expanding the main principles of successful production into the consumption sphere: efficiency, predictability, calculability, and control [86]. This trend has been coined McDonaldization by Ritzer [87] and is based on the idea of rationalization that was developed by classical sociological theorist Max Weber [88], who predicted the extension of rationalization from production to other spheres of life, including consumption. Similar ideas reflecting commoditization, rationalization, and globalization of business models and consumption patterns can be found under the names of McDisneyfication [89] and Coca-Colonization [90]. Another business model that promotes mass consumption is the model for fast moving consumer goods in the discount branch. This model is characterized by a relatively limited choice of products offered at a discounted rate. The continued growth of the discount retail branch indicates that in some spheres of consumption, consumers prefer less choice and lower prices.

Governments can help by supporting innovative business models that are not necessarily built on the premise of selling more material products, but on the idea of creating value and generating profit from satisfying consumer needs through access to, and use of, products [91]. One way to do this is to extend producer responsibility along the entire product life cycle. This would reposition consumers as users, where rather than being purchased, products are hired/leased/rented for as long as the product is needed. A common name for a broad range of innovative business models that are built on this principle is product-service systems (PSS) [92]. Examples of product-service systems already exist in many sectors: car sharing, washing services, chemical management services, demand-side management, least cost planning, etc.

In PSS, consumers pay not to buy material goods, but to use them. Ownership and consumer satisfaction still go hand-in-hand for the majority of people (e.g., car ownership versus use of public transport). Thus, the right package of stimulating and discouraging measures is key to make progress. In this way, there is a decoupling of business profits and consumer spending from material flows in society. This means that low-price, average quality products, with low margins for producers, can be replaced by fewer, high quality products that act as capital assets for producers since they generate functional units, for which consumers are paying. This model thus creates an incentive for producers to design durable products and to foresee product return for disposal, meaning that design for 
remanufacturing and cradle-to-cradle becomes a profitable and natural business [93]. In this way, a cyclic economy can be created with much slimmer material flows and associated environmental and social impacts, and with much lower emissions (since producers can afford to design environmentally sound goods and consumers can afford to pay for using them). The cyclic economy presents a new sphere in each sector of manufacturing, which has the potential to re-create value and create jobs.

However, ecological tax reform is needed to stimulate PSS business models and a closed-loop economy, since they are labor intensive - and current labor costs and taxes on labor are very high in most industrialized countries compared to resources; in the EU, in excess of $80 \%$ of all taxes are income related [94]. The proposal to shift the tax burden from labor to environmental impact and resources creates a win-win situation for employment and for reduced resource use, by encouraging business innovation in energy and resource efficiency.

Together with policies for a more sustainable and low-carbon economy, it is important that governments stimulate environmentally and socially responsible businesses that not only improve their own performance by greening their sites and products, but which also stimulate changes upstream and downstream in the supply chain.

\section{Marketing and Advertising}

Today, consumer choices are strongly influenced by media, advertising, and the behavior of celebrities $[95,96]$. With the increasing consumer exposure to different media channels, such as radio, television, newspapers, and the Internet, the power of media to shape consumer preferences is steadily increasing. Even other cultural media that are not directly associated with advertising, such as public debate, popular music and movies, the visual arts and novels, all shape the way we consume and how we relate to material products.

Besides the increasing pressure and the sheer volume of the advertising industry, there are ongoing changes in the advertising messages and how they are transferred to the simultaneously changing target audience. First of all, the nature of needs that ought to be satisfied by the advertising industry is changing. Since the basic needs of most people in modern industrialized economies are being largely fulfilled, there is a need to continuously create new needs (more information about this phenomenon can be found in Part II of the study). In this task, the role of technological development and innovation is irreplaceable. Designers from a number of IT and white goods companies have revealed that often, a technical solution is invented, and then advertising and marketing is used to create a need among consumers that this invention satisfies, leading to increased consumption of the often material inventions.

As a result of the need to continuously stimulate higher consumption levels, the nature of marketing and advertising is changing. Previously, advertising mostly focused on product performance. Nowadays, advertisement aims to create consumers who are unsatisfied with what they have and therefore advertising increasingly targets feelings, rather than providing information. From being solely a push strategy, advertising is becoming more and more of a pull strategy, e.g., buzz marketing [97]: capturing the attention of consumers and the media to the point where talking about a brand becomes entertaining, fascinating, newsworthy, and desirable. To support this trend, advertising is changing from being mainly verbal to being more visual [98]. Selling feelings rather than 
information is closely linked to another trend of thinking: that not merely products are being sold, but entire lifestyles. Together with the advertisements of specific goods, entire lifestyles and spaces are being advertised; brand names become associated with certain lifestyles, e.g., the Zara or Laura Ashley lifestyle, and companies sell different product lines from clothes to furniture, home styling products, etc. to represent a certain lifestyle. The result is that often, the marketing strategy of products is a stronger determinant of success than product quality [99].

The advertising industry is also expanding its audience, diversifying to children [100] and re-developing gender differences, which creates a playing field for developing and selling products customized for the different target audiences. For example, according to Schor [101], an average 10-year-old has memorized about 400 brands, the average kindergartner can identify some 300 logos, and already from the age of two, kids are "bonded to brands": a two-year old, while not being able to recognize a letter $\mathrm{M}$, has no problem recognizing the golden arches of the McDonalds sign [102].

One of the latest additions to the marketing portfolio is the employment of neuroscience, which enables marketers to understand how consumer decisions are made, even when consumers themselves cannot explain their behavior [65]. One impetus for the application of neuroscience in marketing is that consumers are overloaded with information: "consumers are overwhelmed by commercial messages, and advertisers know it" ([65]: p. 103). Marketers and advertisers are turning to neuroscience to make sure their advertisement reaches the correct part of the brain, and does not get lost within the constant stream of "marketing noise".

To help address the problem of "marketing noise", and to safeguard the truthfulness of the information contained in advertising and marketing, policy measures have been introduced in recent years in many countries to ensure that the consumer information on the market is correct and not misleading. One of the latest additions in this respect is the EU Directive 2006/114/EC concerning misleading and comparative advertising [103]. The latest area that this type of legislation covers is the environmental and ethical claims of companies. It is usually consumer protection agencies that police such claims.

The marketing and advertising strategies currently used to promote non-sustainable consumption patterns could just as easily be used to promote environmentally sound products and more sustainable lifestyles. Advertising tends to be commissioned by businesses, and in turn, many of those businesses rely on high volume sales of material products. It is therefore unsurprising that current advertising and marketing encourages high levels of material consumption. Those companies that have redefined their business models and started promoting alternatives, such as product-service systems, have an alternative message that focuses on increasing value-added for the customer, improving customer satisfaction through establishing long-term relations with them, and securing the function provision for as long as it is required by the customer.

Advertising and marketing are perhaps the most powerful tools that can be employed to create attractive visions of more sustainable futures and lifestyles, products and services, as well as to educate and engage consumers on how to translate these visions into everyday practices. Many examples demonstrate the power of media and advertising in creating more sustainable societies [104]. "If television could transform the entire planet into a global materialistic consumer culture within just 50 years, it could also be used to efficiently promote alternative, non-materialistic lifestyles and 
sustainable consumption. Of course, this would require major changes in the control of mass media and, as discussed below, is likely to be met with strong resistance by many powerful special interests" (Huesemann and Huesemann 2008: p. 815).

\section{Conclusions}

Humanity finds itself in a state of great distress: environmental problems are escalating, disparities between people are widening, and the ecosystem-services the Earth provides are diminishing. Technological solutions that were supposed to solve environmental problems are often outpaced by the increasing consumption levels of the growing minority of the world's population belonging to the consumer society, who frenetically search for sources of new experiences, pleasures, and joys. This paper attempted to describe some of the factors that influence consumer behavior and consumption choices, and the relevance of these factors for instigating changes toward sustainable consumption. Sociological, psychological, and other factors shaping the social fabric of our society are discussed in Part II of the study.

In order to answer these difficult questions about the 'good life' and the course of human progress, it is useful to try to understand the underlying reasons behind people's behavior in relation to consumption. This is especially important for policy makers devising environmental and sustainability policies, since consumption levels and patterns seems to be constant stumbling blocks for progress towards a sustainable society.

This study analyzed a large number of forces that act at institutional and individual levels, which influence each other and affect the way people perceive themselves, their aspirations, and how they undertake and react to changes that might be necessary for achieving a more sustainable society. One of the unsurprising conclusions is that understanding the forces that influence and shape consumption is an incredibly complicated task. Although consumption behavior is complex, failure to address it will result in a failure to bring about the necessary changes in consumer behavior and consumption patterns and levels.

One of the major factors that drives consumption is the main premise of the neoclassical economic paradigm: that continuous economic growth (which is mainly based on ever-increasing growth in production and consumption of material goods) is necessary and desirable. This idea simply cannot work in the world of finite resources, as is also suggested by the economist Kenneth Boulding: "Anyone who believes exponential growth can go on forever in a finite world is either a madman or an economist" [106].

Adopting more sustainable patterns of consumption is an important step, but is definitely not sufficient given the scale of change required to create sustainable consumption [107]. More fundamental systems-level changes are needed in order to reduce overall levels of material consumption. As suggested by Meadows, fundamental changes in society are needed, and the most effective leverage point is to transcend the current paradigm of economic growth and to change the mindset and value basis of society [108].

The importance of systems thinking is also apparent when we consider how to promote sustainable consumption. The limits of the spill-over effect on sustainable behaviors and the limits of efficiency measures (as demonstrated by rebounds effects) make it necessary to target entire ways of life that are 
currently based on normalized unsustainable consumption, rather than focusing on changing individual behaviors. Similarly, a focus at the individual level is misguided: the social norms and values underlying mainstream society have the most significant impact on consumption behavior; thus, policy intervention should take place at this level.

If the main goal of societal development, economic and infrastructure growth, and business development is to create a healthy society with happy and satisfied people, then it seems that the current system pursuing GDP growth at any cost, in failing to deliver consistent improvements in well being, has failed on its own terms [109]. Sociological and psychological studies demonstrate that in order to be happy, people need to have their basic needs satisfied (see Part II on how "needs" are socially constructed and continually increasing), but it is equally important that their entire lives should not be spent in constant pursuit of material wealth; many examples indicate than when faced with conditions that allow people in the Western world to reassess their work life balance, a significant number choose to work fewer hours for a reduced income.

A number of policy interventions are known to motivate more sustainable consumption, for example, Ecological Tax Reform. Although many of these interventions are well known, tested and documented, governments may feel constrained in their ability to implement more radical reforms - reforms on the scale required by the environmental challenges faced - due to current lack of public support and intense lobbying from industry and private stakeholders. Again, this leads to the conclusion that technical policy interventions alone will prove insufficient for society to achieve sustainable consumption patterns: a paradigm shift which redefines the values and norms that underlie the way we choose to live is required. Therefore, it is important to not only consider formal institutional factors that influence and shape consumption, but also factors of individual and collective human behavior that guide their consumption. These factors are discussed in Part II of this paper.

\section{References and Notes}

1. Tukker, A.; Huppes, G.; Guinée, J.; Heijungs, R.; de Koning, A.; Van Oers, L.; Suh, S.; Geerken, T.; Van Holderbeke, M.; Jansen, B. et al. Environmental Impact of Products (EIPRO): Analysis of the Life Cycle Environmental Impacts Related to the Final Consumption of the EU-25; JRC/IPTS/ESTO: Seville, Spain, 2006.

2. Household Consumption and the Environment; European Environmental Agency: Copenhagen, Denmark, 2005; p. 72.

3. Silberberg, E. The Structure of Economics: A Mathematical Analysis; McGraw-Hill: New York, NY, USA, 1978.

4. Norton, B., Costanza, R.; Bishop, R.C. The evolution of preferences-Why 'sovereign' preferences may not lead to sustainable policies and what to do about it. Ecol. Econ. 1998, 24, 193-211.

5. Michaelis, L. Drivers of consumption patterns. In Towards Sustainable Consumption: A European Perspective; The Royal Society: London, UK, 2000; p. 12.

6. Lancaster, K. Consumer Demand: A New Approach (Study in Economics: No. 5); Columbia University Press: New York, NY, USA, 1971. 
7. Michael, R.T.; Becker, G.S. On the new theory of consumer behavior. Swed. J. Econ. 1973, 75, 378-396.

8. Toumanoff, P.; Farrokh, N. A Mathematical Approach to Economic Analysis; West Publishing Company: Minnesota, MN, USA, 1994.

9. Becker, G.S. A theory of the allocation of time. Econ. J. 1965, 75, 493-517.

10. Easterlin, R.A. Does money buy happiness? Public Interest 1973, 3, 3-10.

11. Ausubel, J.H.; Grubler, A. Working less and living longer: Long-term trends in working time and time budgets. Technol. Forecast. Soc. Change 1995, 50, 113-131.

12. Sanne, C. The consumption of our discontent. Business Strategy Environ. 2005, 14, 315-323.

13. Coote, A.; Simms, A.; Franklin, J. 21 Hours: Why a Shorter Working Week Can Help Us All to Flourish in the 21st Century; Murphy, M., Ed.; New Economics Foundation: London, UK, 2010; p. 40.

14. Barata, J.M.; Pacheco, L.M. Asset prices and monetary policy: Wealth effects on consumption. In Proceedings of the 20th Symposium on Banking and Monetary Economics, Lisbon, Portugal, 5-6 June 2003.

15. Iacoviello, M. Consumption, house prices, and collateral constraints: A structural econometric analysis. J. Hous. Econ. 2004, 13, 304-320.

16. Cohen, M.J. Consumer credit, household financial management, and sustainable consumption. Int. J. Consum. Stud. 2007, 31, 57-65.

17. Segal, J.M. Graceful Simplicity. Toward a Philosophy \& Politics of Simple Living; Henry Holt: New York, NY, USA, 2003.

18. Sanches, S. Sustainable consumption à la française? Conventional, innovative, and alternative approaches to sustainability and consumption in France. Sustain. Sci. Pract. Policy 2005, 1, 1-15.

19. Jalas, M. A time use perspective on the materials intensity of consumption. Ecol. Econ. 2002, 41, 109-123.

20. Bureau of Labor Statistics. American Time Use Survey-2008 Results; Available online: http://www.bls.gov/tus/home.htm 2008 (accessed on 8 October 2009).

21. Geiger, S. Exploring night-time grocery shopping behavior. J. Retail. Consum. Serv. 2007, 14, 24-35.

22. Durning, A.T. Are we happy yet? In Ecopsychology: Restoring the Earth, Healing the Mind; Roszak, T., Gomes, M.E., Kanner, A.D., Eds.; Sierra Club Books: San Francisco, CA, USA, 1995; pp. 68-76.

23. Elgin, D. Voluntary Simplicity: Toward a Way of Life That Is Outwardly Simple, Inwardly Rich; William Morrow \& Co.: New York, NY, USA, 1981.

24. Wachtel, P.L. The Poverty of Affluence: A Psychological Portrait of the American Way of Life; Free Press/Macmillan: New York, NY, USA, 1983.

25. Dominguez, J.; Robin, V. Your Money or Your Life: Transforming Your Relationship with Money and Achieving Financial Independence; Penguin Books: New York, NY, USA, 1993.

26. Schor, J. The Overspent American: Why We Want What We Don't Need; Harper Perennial: New York, NY, USA, 1999.

27. Ekins, P.; Max-Neef, M. Real Life Economics: Understanding Wealth Creation; Routledge: London, UK, 1992. 
28. Healthier, Safer, More Confident Citizens: A Health and Consumer Protection Strategy; Commission of the European Communities: Brussels, Belgium, 2005; p.74.

29. A citizens' agenda. In Delivering Results for Europe; Commission of the European Communities: Brussels, Belgium, 2007; p. 10.

30. Green Paper on Innovation: 1995; Commission of the European Communities: Brussels, Belgium, 1995; p. 52.

31. Sorrell, S. The Rebound Effect: An Assessment of the Evidence for Economy-Wide Energy Savings from Improved Energy Efficiency; UK Energy Research Center: Sussex, UK, 2007; p. 123.

32. Hertwich, E.G. Consumption and the rebound effect: An industrial ecology perspective. J. Ind. Ecol. 2005, 9, 85-99.

33. Berkhout, P.H.G.; Muskens, J.C.; Velthuijsen, J.W. Defining the rebound effect. Energy Policy 2000, 28, 425-432.

34. Cooper, T. Slower consumption: Reflections on product life spans and the throwaway society. J. Ind. Ecol. 2005, 9, 51-70.

35. Holt, K. Market Oriented Product Innovation: A Key to Survival in the Third Millennium; Kluwer Academic Publisher: Doordrecht, The Netherlands, 2002.

36. Vergragt, P.J. System Innovation for Sustainability. Perspectives on Radical Change to Sustainable Consumption and Production; Tukker, A., Charter, M., Vezzoli, C., Stø, E., Andersen, M.M., Eds.; Greenleaf Publishing: Sheffield, UK, 2009.

37. Hill, H. Food Miles: Background and Marketing, ATTRA—National Sustainable Agriculture Information Service; Available online: www.attra.ncat.org/attra-pub/foodmiles.html (accessed on 1 December 2008).

38. Görres, A.; Cottrell, J. The tragic paradox: Germany's very successful but not very popular green budget reform: Lessons from seven years of courageous turnaround (1999-2005). In Critical Issues in Environmental Taxation: International and Comparative Perspectives; Chalifour, N.J., Milne, J.E., Ashiabor, H., Deketelaere, K., Kreiser, L., Eds.; Oxford University Press: Oxford, UK, 2008; pp. 701-722.

39. Tukker, A.; Diaz-Lopez, F.;Van de Lindt, M.; Mont, O.; Lorek, S.; Spangenberg, J.; Giljum, S.; Bruckner, M.; Oman, I. Sustainable Consumption Policies Effectiveness Evaluation (SCOPE2); Report to European Commission within FP6: Brussels, Belgium, 2008; p. 122.

40. Gee, D. Economic Tax Reform in Europe: Opportunities and Obstacles; In Ecotaxation; O’Riordan, T., Ed.; Earthscan: London, UK, 1997.

41. Beuermann, C.; Santarius, T. Ecological tax reform in Germany: Handling two hot potatoes at the same time. Energy Policy 2006, 34, 917-929.

42. Deroubaix, J.F.; Leveque, F. The rise and fall of French ecological tax reform: Social acceptability versus political feasibility in the energy tax implementation process. Energy Policy 2006, 34, 940-949.

43. Klok, J.; Larsen, A.; Dahl, A.; Hansen, K. Ecological tax reform in Denmark: History and social acceptability. Energy Policy 2006, 34, 905-916.

44. Dresner, S.; Jackson, T.; Gilbert, N. History and social responses to environmental tax reform in the United Kingdom. Energy Policy 2006, 34, 930-939. 
45. The Benefits of and Barriers to Ecological Tax Reform; European Environmental Agency: Copenhagen, Denmark, 2009; p. 6.

46. Household Behavior and the Environment Reviewing the Evidence; OECD: Paris, France, 2008; p. 264.

47. Salzman, J. Informing the green consumer. The debate over the use and abuse of environmental labels. J. Ind. Ecol. 1997, 1, 11-21.

48. Leire, C.; Thidell, $\AA$. Product-related environmental information to guide consumer purchases-A review and analysis of research on perceptions, understanding and use among Nordic consumers. J. Clean. Prod. 2005, 13, 1061-1070.

49. Kollmuss, A.; Agyeman, J. Mind the gap: Why do people act environmentally and what are the barriers to pro-environmental behavior? Environ. Educ. Res. 2002, 8, 239-260.

50. Pedersen, E.R.; Neergaard, P. Caveat emptor-Let the buyer beware! environmental labeling and the limitations of "green" consumerism. Business Strategy Environ. 2006, 15, 15-29.

51. Crompton, T.; Thøgersen, J. Simple and painless? The limitations of spillover in environmental campaigning. Available online: http://assets.wwf.org.uk/downloads/simple_painless_report.pdf (accessed on 8 July 2009).

52. Holdsworth, M. Green Choice: What Choice? National Consumer Council: London, UK, 2003.

53. Peattie, K. Golden goose or wild goose? The hunt for the green consumer. Business Strategy Environ. 2001, 10, 187-199.

54. Grübler, A. Industrialization as a historical phenomenon. In Industrial Ecology and Global Change; Socolow, R., Andrews, C., Berkhout, F., Thomas, V., Eds.; Cambridge University Press: New York, NY, USA, 1997; pp. 43-68.

55. Braun, E. Futile Progress: Technology's Empty Promise; Earthscan Publications: London, UK, 1995.

56. Technological Change and the Environment; Grübler, A., Nakicenovic, N., Nordhaus, W.D., Eds.; Resources for the Future: Washington, DC, USA, 2002.

57. McKeown, T. The Origins of Human Disease; Basil Blackwell: New York, NY, USA, 1988.

58. Ehrlich, P.R.; Ehrlich, A.H. The Population Explosion; Touchstone Books: Florida, FL, USA, 1991.

59. Pimentel, D.; Pimentel, M. Food, Energy, and Society; University of Colorado Press: Boulder, CO, USA, 1996.

60. Cooper, T. Durable consumption: Reflections on product life cycles and the throwaway society. In Proceedings the the Workshop on Life-cycle Approaches to Sustainable Consumption, Vienna, Austria, 22 November 2002; IIASA: Laxenburg, Austria, 2002.

61. Stahel, W.; Reday, G. Jobs for Tomorrow, the Potential for Substituting Manpower for Energy; Vantage Press: Brussels, Belgium, 1976/1981.

62. Green Guidance; Consumers International: London, UK, 1998.

63. State of the Art Survey-Consumption Theories (Achieving Sustainability by using Substitutive Information Society Technology); European Commission: Brussels, Belgium, 2001; p. 104.

64. Gadgets and Gigawatts-Policies for Energy Efficient Electronics; International Energy Agency: Paris, France, 2009; p. 426. 
65. Belch, G.E.; Belch, M.A. Advertising and Promotion: An Integrated Marketing and Communications Perspective; McGraw-Hill/Irwin: New York, NY, USA, 2007.

66. Andersen, M.M. An Innovation system approach to eco-innovation-Aligning policy rationales. In Proceedings of the Greening of Policies-Interlinkages and Policy Integration Conference, Berlin, Germany, 3 December 2004.

67. Bauman, Z. Going about the business of life. In Thinking Sociologically; Bauman, Z., Ed.; Blackwell: Oxford, UK, 1990.

68. Otnes, P. Housing consumption: Collective systems service. In The Sociology of Consumption; Otnes, P., Ed.; Humanities Press: Atlantic Highlands, NJ, USA; pp. 119-138.

69. Warde, A. Noticing Inconspicuous Consumption. Workshop 1: Consumption, Everyday Life and Sustainability, ESF-Term Programme: Consumption, Everyday Life and Sustainability Summer School, 1999; Lancaster University: Lancaster, UK, 1997.

70. Cowan, R.S. More Work for Mother: The Ironies of Household Technology from the Open Hearth to the Microwave; Basic Books: New York, NY, USA, 1983.

71. Van Vliet, B.; Chappells, H.; Shove, E. Infrastructures of Consumption. Environmental Innovation in the Utility Industries; Earthscan: London, UK, 2005.

72. Arthur, W.B. Increasing Returns and Path Dependence in the Economy; Michigan University Press: Ann Arbor, MI, USA, 1994.

73. Sanne, C. Willing consumers or locked-in? Ecol. Econ. 2002, 42, 273-287.

74. Chappells, H.; Klintman, M.; Lindon, A.L.; Shove, E.; Spaargaren, G.; van Vliet, B. Domestic Consumption, Utility Services and the Environment; Wageningen University: Wageningen, The Netherlands, 2000; p. 181.

75. Platt, R.; Retallack, S. Consumer Power. How the Public Thinks Lower-Carbon Behavior Could Be Made Mainstream; Institute for Public Policy Research: London, UK, 2009; p. 47.

76. Sustainable Consumption. The Implications of Changing Infrastructures of Provision; Southerton, D., Chappels, H., van Vliet, B., Eds.; Edward Elgar Publishing: Northampton, MA, USA, 2004.

77. Conclusion of the Chair. In Proceedings of the 4th Workshop of the International Feed-in Cooperation, Ljubljana, Slovenia, 18-19 October 2007.

78. Heaps, C.; Erickson, P.; Kartha, S.; Kemp-Benedict, E. Europe's Share of the Climate Challenge. Domestic Actions and International Obligations to Protect the Planet; Stockholm Environment Institute: Stockholm, Sweden, 2009; p.68.

79. Lehner, F.; Bierter, W.; Charles, T. Factor 10: Resource Productivity, Competitiveness, and Employment. In The Advanced Economies. Carnoules; Available online: http://www.factor10institute.org/files/Factor_10_Report_2000_Chapter3.pdf (accessed on 15 July 2010).

80. Bulow, J. An economic theory of planned obsolescence. Quart. J. Econ. 1986, 101, 729-750.

81. Fishman, A.; Gandal, N.; Shy, O. Planned obsolescence as an engine of technological progress. J. Ind. Econ. 1993, XLI, 361-370.

82. Whiteley, N. Design for Society; Reaktion Books: London, UK, 1993.

83. Wells, P.; Seitz, M. Business models and closed-loop supply chains: A typology. Supply Chain Manag. 2005, 10, 249-251.

84. Stahel, W. The Performance Economy; Palgrave-Macmillan: London, UK, 2006. 
85. Stahel, W. The utilization-focused service economy: Resource efficiency and product-life extension. In The Greening of Industrial Ecosystems; Allenby, B.R., Ed.; National Academy Press: Washington, DC, USA, 1994; pp. 178-190.

86. Ritzer, G.; Ovadia, S. The process of McDonaldization is not uniform, nor are its settings, consumers, or the consumption of its goods and services. In New Forms of Consumption: Consumers, Culture, and Commodification; Gottdiener, M., Ed.; Rowman \& Littlefield: Lanham, MD, USA, 2000; pp. 33-49.

87. Ritzer, G. The McDonaldization of Society; Pine Forge Press: London, UK, 1993.

88. Weber, M. Economy and Society: An Outline of Interpretive Sociology; Bedminster Press: New York, NY, USA.

89. Bryman, A. Theme parks and McDonaldization. In Resisting McDonaldization; Smart, B., Ed.; Sage: London, UK, 1998; pp. 101-115.

90. Prendergrast, M. For God, Country and Coca-Cola: The Unauthorized History of the Great American Soft Drink and the Company that Makes It; Maxwell Macmillan: Toronto, Canada, 1993.

91. Mont, O. Reaching Sustainable Consumption through the Concept of a Product-Service System (PSS); Nordic Council of Ministers: Copenhagen, Denmark, 2001.

92. Goedkoop, M.J.; van Halen, C.J.G.; te Riele, H.R.M.; Rommens, P.J.M. Product Service Systems, Ecological and Economic Basis; Technical Report; Pre Consultants: Amersfoort, The Netherlands, 1999.

93. Mont, O. Introducing and Developing a Product-Service System (PSS) Concept in Sweden; IIIEE, Lund University: Lund, Sweden, 2001; p. 124.

94. Paleocrassas, Y. Factor 10 Fiscal Reform, Resource Productivity, and Employment. Available online: http://www.factor10-institute.org/files/Factor_10_Report_2000_Chapter2.pdf (accessed on 15 July 2010).

95. Henderson, A. From Barnum to "Bling Bling": The changing face of celebrity culture. Hedgehog Rev. Crit. Reflect. Contemp. Culture 2005, 7, 37-46.

96. Boykoff, M.T.; Goodman, M.K. Conspicuous redemption? Reflections on the promises and perils of the 'Celebritization' of climate change. Geoforum 2009, 40, 395-406.

97. Kotler, P.; Wong, V.; Armstrong, G.; Saunders, J. Principles of Marketing; The University of South Carolina: Columbia, SC, USA, 2005.

98. Söderlund, M. I huvudet på konsumenten. Forskning och Framste 2006, 8, 36-38; Available online: http://www.fof.se/tidning/2006/8/i-huvudet-pa-konsumenten (accessed on 15 July 2010).

99. Dahlén, M.; Lange, F. Optimal Marknadskommunikation; Liber Ekonomi: Malmö, Sweden, 2003.

100. Benjamin, R.B. Consumed: How Markets Corrupt Children, Infantilize Adults, and Swollow Citizens Whole; W.W. Norton: München, Germany, 2007; pp. 293-297.

101. Schor, J.B. Born to Buy. The Commercialized Child and the New Consumer Culture; Scribner: New York, NY, USA, 2004.

102. State of the World 2010-Transforming Cultures: From Consumerism to Sustainability; Worldwatch Institute: Washington, DC, USA, 2010. 
103. Commission of European Communities. Directive 2006/114/EC of the European Parliament and of the Council of 12 December 2006 concerning misleading and comparative advertising. Offic. J. Eur. Union 2006, 376, 21-27.

104. Promoting Sustainable Consumption. Good Practices in OECD Countries; OECD: Paris, France, 2008; p. 62.

105. Huesemann, M.H.; Huesemann, J.A. Will progress in science and technology avert or accelerate global collapse? A critical analysis and policy recommendations. Environ. Dev. Sustain. 2008, 10, 787-825.

106. The Great Transition. A Tale of How it Turned Out Right; New Economics Foundation: London, UK, 2009; p. 128.

107. Alfredsson, E.C. "Green" consumption-No solution for climate change. Energy 2004, 29, 513-524.

108. Meadows, D. Leverage Points: Places to Intervene in a System; The Sustainability Institute: Hartland, VT, USA, 1999.

109. The Earthscan Reader on Sustainable Consumption; Jackson, T., Ed.; Earthscan Reader Series: London, UK, 2006; p. 402.

(C) 2010 by the authors; licensee MDPI, Basel, Switzerland. This article is an Open Access article distributed under the terms and conditions of the Creative Commons Attribution license (http://creativecommons.org/licenses/by/3.0/). 